\title{
Assessing Site Selection of New Towns Using TOPSIS Method under Entropy Logic: A Case study: New Towns of Tehran Metropolitan Region (TMR)
}

\author{
Asad Asadzadeh (Corresponding author) \\ Dept. of Urban Planning and Land Management, University of Bonn \\ Post code: 53115, Nußallee 1, Bonn, Germany \\ Tel: 49-228-73-3584Ｅ-mail: asad.asadzadeh@uni-bonn.de \\ Sujit Kumar Sikder \\ Dept. of Urban Planning and Land Management, University of Bonn \\ Post code: 53115, Nußallee 1, Bonn, Germany \\ Tel: 49-228-73-3705Ｅ-mail: sikder@uni-bonn.de
}

Farzin Mahmoudi

Faculty of Urban Planning, University of Mazandaran

Post code: Pasdaran Street, 47415, Babolsar, Iran

Tel: 98-1125-2320-9195Ｅ-mail: farzinmahmoudi@gmail.com

Theo Kötter

Dept. of Urban Planning and Land Management, University of Bonn

Post code: 53115, Nußallee 1, Bonn, Germany

Tel: 49-228-73-2612Ｅ-mail: koetter@uni-bonn.de

Received: January 6, 2014 Accepted: January 19, 2014

doi:10.5296/emsd.v3i1.4874 URL: http://dx.doi.org/10.5296/emsd.v3i1.4874 


\section{$\Lambda$ Macrothink}

\section{Abstract}

Location planning process as one of the most complicated spatial decisions is the initial and perhaps one of the critical steps in the development of a New Town. Site selection (seat and location) is a fundamental factor in success of new towns functionality, and also determines the success of the new town investment. Since location planning and selecting a well-fit option from the feasible alternatives is a significant problem in every decision making process, Multi Criteria Decision Making (MCDM) has been found to be an efficient approach to solve this kind of problems. There are different MCDM models that have been applied for site selection projects in both urban and regional scales. But simultaneous application of quantitative and quantitative criteria and weighting (importance coefficient) of indicators according to regional features and theoretical principles, make TOPSIS as an optimal model to assess site selection projects. This method emphasizes that selected alternative should have the least distance with positive idea solution (the best possible site) and the most distance with negative ideal solution (the worst possible site). In this paper, using technique for order preference by similarity to ideal solution (TOPSIS) we intended to evaluate site selection of New Towns of Tehran Metropolitan Region (TMR) to show their overall situation to optimal alternative (site selection).

Keywords: Site selection; New Towns; MCDM; TOPSIS; Entropy

\section{Introduction}

Site selection subject and determining the most appropriate location for lodgment is one of the most important establishment steps of these biological settlements (Banietemad, 1992). Its effects are appeared in long term period and have significant consequences in economic, social and environmental aspects. In optimal site selection process for settlements, after determination of overall and operational objectives and also determination of alternatives, the evaluation is done and based on relative eligibility of each alternative, the desirable option is selected (Zebardast,2001). This process involves several steps but considering location and position features are the first step. In according with urban upstream plans, regional development strategies, access and accessibility and site development potentials are some important factors that should be considered in new towns site selection (Mandelker, 1965). Moreover, Factors such as availability of a water supply, sufficiency of existing connecting roads, availability of such utility services as gas and electricity, potentialities for sewage disposal and the suitability of the land for development are usually considered (Mcfarland, 1965). However, site location problem usually involves a set of locations (alternatives) which are evaluated against a set of weighted criteria independent from each other. The alternative that performs best with respect to all criteria is chosen for implementation (Awasthi, 2011). Therefore site selection can be viewed as a Multiple Criteria Decision-Making or Multiple Attributes Decision-Making (MCDM/MADM) problems. The MCDM or MADM is the approach dealing with the ranking and selection of one or more sites from the alternatives. MCDM methods have been developed to assist decision makers in either ranking a known set of alternatives for a problem or making a choice among this set while considering the conflicting criteria (Sumathi et al, 2008). 


\section{MInstitute Macrothink $_{\text {Int }}^{\text {Intis }}$}

Since the 1950s, MCDM methods have been proposed as a major tool to assist decision makers with analyzing and solving multiple criteria decision problems. Some of the important methods of MCDM have been summarized by Kenney and Raiffa (1976), Zeleny (1982) and Yoon \&Hwang (1995). Recently many researchers have conducted literatures to determine the appropriate site selection using different MCDM methods. Siddiquiet al. (1996) were one of the first pioneers to use a combined geographical information system (GIS) and analytical hierarchy process (AHP) procedure to aid in site selection. Chen. (2001) developed a fuzzy multi-attribute decision making approach for the distribution center location selection problem. Chu (2002) has applied a fuzzy TOPSIS model to solve the facility location selection problem under group decision making. Kahraman et al. (2003) used four fuzzy multi attribute group decision making approaches in evaluating facility locations. Chou et al. (2008) have presented a fuzzy simple additive weighting system under group decision making for facility location selection with objective and subjective attributes. Zhou and $\mathrm{Wu}$ (2012) have applied GIS-based multi criteria analyzing for site selection of hospitals in Beijing. More recently, Ding and Chou (2013) have applied the fuzzy multi criteria decision making for location selection of transshipment ports.

In most site selection projects, it is very difficult to develop selection indicators that can exactly represent the preference of one site over other. Here, as different scales participate and the decisions are made in multidimensional space, the election of appropriate method for assessing of desired alternatives is very important. For instance, in site selection projects the attributes have increasing or decreasing influence to each other (e.g., appropriate access to main communication network can compensate the high distance from industrial towns or economic activity centers). Hence, unlike traditional operations research optimization problems, which deal with a single objective function to be optimized over a set of feasible solutions, MCDM refers to making decisions in the presence of multiple, usually conflicting and non-commensurable criteria (Zanakiset al, 1998). MCDM methods have been developed to assist decision makers in either ranking a known set of alternatives for a problem or making a choice among this set while considering the conflicting criteria (Sumathi, 2008). Among from MCDM methods, the Technique for Order Preference by Similarity to the Ideal Solution (TOPSIS) is one of the well - known classic MCDM methods. The TOPSIS method is selected because of its unique (specific) but also very logical way of approaching the discrete MCDM problems. This technique emphasizes that the selected alternative should have the least distance with a positive ideal solution (the best possible site) and the most distance with negative ideal solution(the worst possible site).

Nevertheless, although many studies have been applied to determine an appropriate site in urban and regional scales, the lack of such studies in site selection project of new towns is completely evident. So that, after three decades from new towns strategy in Iran, many urban scholars believe that rather than standard scientific approach, political and administrative factors had more important role in decision making process of new towns site selection (Goharrizi, 2013). Therefore, this paper can be kind of after implementation evaluation based on TOPSIS and entropy logic to re-evaluating the site selection of new towns of Tehran City. The rest of the paper is organized as follows: In section 2, an overview on methodology 


\section{Macrothink}

Environmental Management and Sustainable Development

ISSN 2164-7682

2014, Vol. 3, No. 1

including understanding of TOPSIS and important factors to consider for TOPSIS application, is presented. In section 3, an empirical case study on Tehran Metropolitan Region (TMR) TMR is presented. Finally, in section 4 is concluded by summing up the whole study.

\section{Study Methodology}

The evaluation procedure of the study is shown in Fig. 1. After determining the problem and defining the research objective and reviewing related literatures, the considered method is identified. Then the evaluation indicators of new towns site selection are determined. According to these criteria, the required data utilized in the comparisons are gathered from the related organizations. After that, the Entropy is used to weighting of criteria. In continuous, the obtained weights or the importance co-efficient of each attributes are combined with the expert's opinions. Finally TOPSIS algorithm is applied to achieve final ranking results. The detailed descriptions of major steps are elaborated in the following subsections.

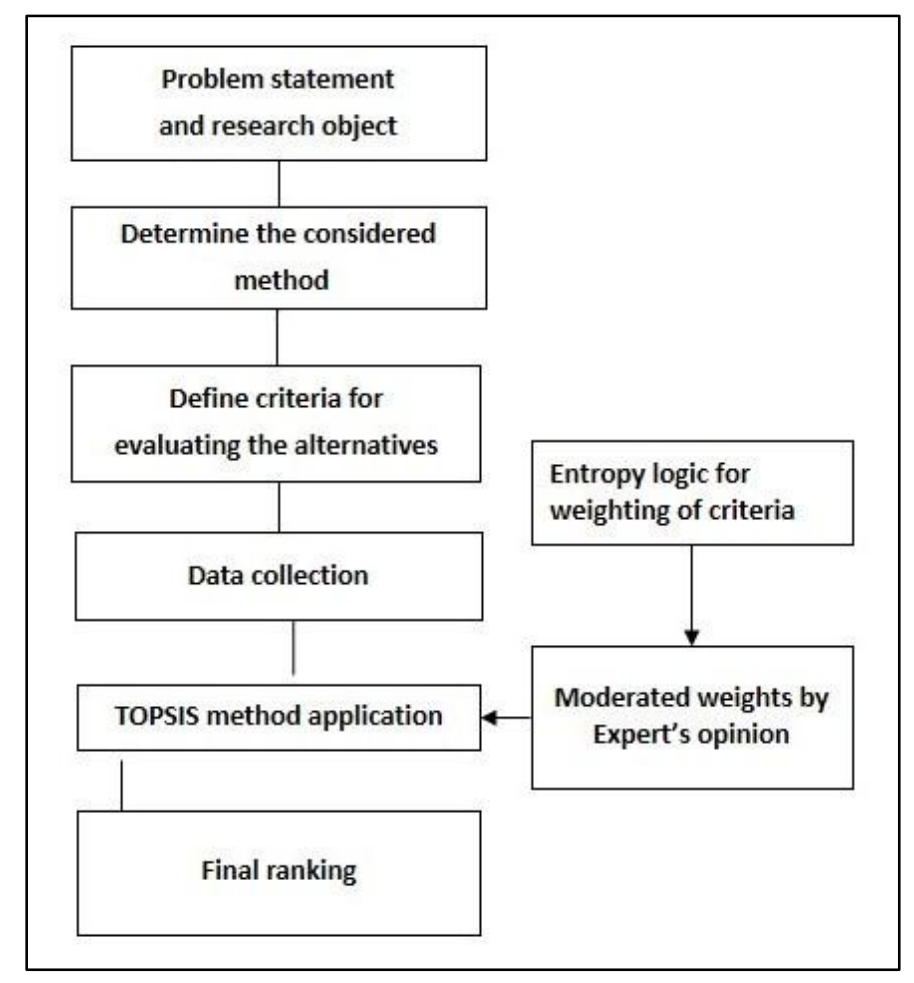

Figure1. Overall process of study

\subsection{TOPSIS: What and How?}

Technique for order preference by similarity to ideal solution (TOPSIS) is one of the classical methods of MCDM that $\mathrm{m}$ alternative is computed by $\mathrm{n}$ attribute and every problem is considered as a geometrical system consisting of $m$ point in $n$ dimensional space (Yang. 2007). TOPSIS is a widely accepted multi attribute decision-making technique due to its sound logic, simultaneous consideration of the Ideal and the anti-ideal solutions and easily programmable computation procedure (Onüt and Soner, 2008). This technique is based on the concept that 


\section{Macrothink}

selected alternative should have the least distance with a positive idea solution (the best possible site) and the most distance with negative ideal solution( the worst possible site).

In methods that alternatives are just compared with regard to the ideal solution option, the preferable alternative will be the alternative that has shortest distance with the ideal solution option (in comparison with other alternative). Whereas it is probable that this alternative has not obtained the desirable condition. Therefore, relative distance of options to positive and negative ideal solution will provide the possibility of real evaluation and analysis of alternatives. The TOPSIS procedure consists of the following steps:

Step 1: Transform decision matrix into the dimensionless matrix with using of relation

$$
n_{i j}=\frac{r_{i j}}{\sqrt{\sum_{i=1}^{m} r_{i j}^{2}}}
$$

Step 2: Construct the Weighted Normalized Decision Matrix

$$
V=N_{D} \cdot W_{n \times n}=\left|\begin{array}{cc}
V_{11} \ldots \ldots . V_{1 j}, \ldots \ldots V_{1 n} \\
\cdot & \cdot \\
\cdot & \cdot \\
V_{m 1}, \ldots . . V_{m j}, \ldots . . V_{m n}
\end{array}\right|
$$

$\mathrm{N}_{\mathrm{D}}$ is a matrix where the weight of criteria have been normalized and $\mathrm{W}_{\mathrm{n} \times \mathrm{n}}$ is a diagonal matrix.

Step 3: Determine the Ideal and Negative-Ideal solutions

$$
\begin{aligned}
& A^{+}=\left\{\left(\max _{i} V_{i j} \mid j \in J\right),\left(\min _{i} V_{i j} \mid j \in J^{\prime}\right) \mid i=1,2, \ldots \ldots . m\right\}=\left\{V_{1}^{+}, V_{2}^{+}, \ldots \ldots . V_{j}^{+}, \ldots \ldots \ldots . V_{n}^{+}\right\} \\
& A^{-}=\left\{\left(\min _{i} V_{i j} \mid j \in J\right),\left(\max _{i} V_{i j} \mid j \in J^{\prime}\right) \mid i=1,2, \ldots \ldots . m\right\}=\left\{V_{1}^{-}, V_{2}^{-}, \ldots \ldots . V_{j}^{-}, \ldots \ldots \ldots ., V_{n}^{-}\right\}
\end{aligned}
$$

Step 4: Calculate the Separation Measure (from positive and negative ideal solution)

$$
\begin{aligned}
& \mathrm{d}_{\mathrm{i}+}=\left\{\sum_{j=1}^{n}\left(\mathrm{~V}_{\mathrm{ij}}-\mathrm{V}^{+}{ }_{\mathrm{j}}\right)^{2}\right\}^{0.5}, \mathbf{i}=1,2, \ldots \ldots ., \mathbf{m} \\
& \mathrm{d}_{\mathrm{i}-}=\left\{\sum_{j=1}^{n}\left(\mathrm{~V}_{\mathrm{ij}}-\mathrm{V}^{-}{ }_{\mathrm{j}}\right)^{2}\right\}^{0.5}, \mathrm{i}=1,2, \ldots \ldots . ., \mathrm{m}
\end{aligned}
$$

Step 5: Calculate the Relative Closeness for the Ideal Solution

$$
c l i+=\frac{d_{i-}}{\left(d_{i+}+\mathrm{d}_{\mathrm{i}-}\right)} \quad, \quad 0 \leq \mathrm{cl}_{\mathrm{i}+} \leq 1 \quad, \quad \mathrm{i}=1,2, \ldots \ldots \ldots, \mathrm{m}
$$

Step 6: Rank the Preference Order: The best (optimal) alternative can be decided according to the preference rank order of (cli+). 


\section{Macrothink \\ Environmental Management and Sustainable Development \\ ISSN 2164-7682 \\ 2014, Vol. 3, No. 1}

\subsection{Important Factors in Application of TOPSIS}

2.2.1 The indicators measurement scale and quantification of qualitative criteria

An alternative in MADM may be described by quantitative and qualitative indicators. Therefore, implementation of mathematical calculations without translation of qualitative attributes to quantitative indicators is not allowed. The most commonly used scale is interval scale that is shown on below Table 1.In addition, the numbers 2, 4, 6 and 8 are as intermediate values.

Table 1. Transformation of qualitative indicators into quantitative

\begin{tabular}{|c|c|c|c|c|c|c|}
\hline $\begin{array}{c}\text { Qualitative } \\
\text { Estimation }\end{array}$ & Bad & Good & average & Very good & excellent & $\begin{array}{c}\text { Type of } \\
\text { criteria }\end{array}$ \\
\hline $\begin{array}{c}\text { Quantitative } \\
\text { estimation }\end{array}$ & 9 & 7 & 5 & 3 & 1 & $\min$ \\
\cline { 2 - 7 } & 1 & 3 & 5 & 7 & 9 & $\max$ \\
\hline
\end{tabular}

2.2.2 Normalization (Dimension less matrix)

In order for application of initial matrix and comparison of different measurement scales, it is necessary to normalize the attribute values. In this step the attribute values are measured as non-dimensional. Vector normalization and linear normalization are two main normalization methods in MCDM methods.

\subsubsection{Evaluation of weights (importance coefficient) for attributes}

The importance (weight) of attributes can be determined by using different procedures. Broadly there can be analytical, simulation or empirical (heuristic) procedures. The last, the entropy method is often recommended as a convenient method for eliminating criteria with similar values and thus highlighting the importance of criteria with higher differences in their values (Hwang and Yoon, 1981). Application of these methods helps to compare the attributes importance with each other and also provide the possibility of weights modification according to scientific and empirical principles.

Entropy is a major meaning in physical and social science to showing the amount of disorder in a system or the measure of the amount of energy in physical system not available to do work. In statistical mechanics the interpretation is more general perhaps, where the entropy becomes a function of statistical probability. In that case, the entropy is a measure of the probability for given macro state, so that high entropy indicates a high probability state and low entropy indicates a low probability state (Markovic, 2010). A decision making matrix contains information that entropy can be applied as scale for evaluation of these data (Asgharpour, 2004).

MCDM problem can be concisely expressed in matrix format as follows where $A_{1}, A_{2}$ and $A_{m}$ are possible alternative and $X_{1}, X_{2}$ and $X_{n}$ are indicators. 


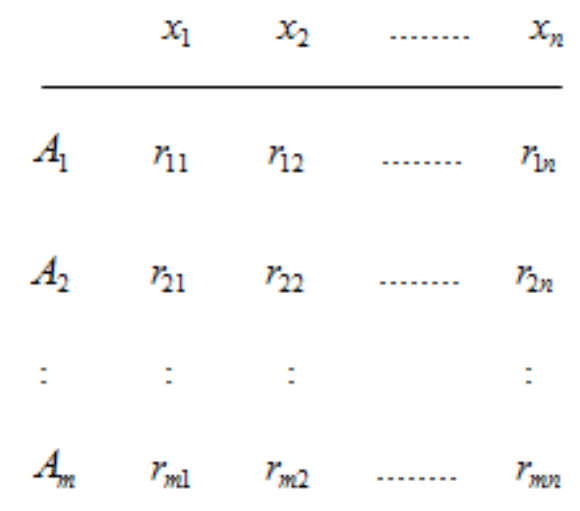

Firstly, the information of this matrix should be calculated as (Pij):

$$
P_{i j}=\frac{r_{i j}}{\sum_{i=1}^{m} r_{i j}} \quad, \quad \forall i, j
$$

And for $(\mathrm{Ej})$ from $(\mathrm{Pj})$ set and for each attribute, we will have:

$$
\mathrm{E}_{\mathrm{j}}=-k \sum_{i=1}^{m}\left[P_{i j} \cdot \operatorname{Ln} P_{i j}\right] \quad, \quad \forall j_{k}=\frac{1}{\mathbf{L n ~} \mathbf{m}}
$$

Now, uncertainly deviation degree of $(\mathrm{Dj})$ from the calculated data per $\mathrm{j}$ attribute is simply:

$$
\mathrm{d}_{\mathrm{j}}=1-E_{j} \quad, \quad \forall{ }_{j}
$$

Finally for weights $(\mathrm{Wj})$ from the available attributes, we will have,

$$
\mathrm{w}_{\mathrm{j}}=\frac{\mathrm{d}_{\mathrm{j}}}{\sum_{j=1}^{\mathrm{n}} \mathrm{d}_{\mathrm{j}}} \quad, \quad \forall j
$$

If DM (decision makers) have an intrinsic judgment $\left(\lambda_{j}\right)$ as relative importance for $\mathrm{j}$ attribute, then it is possible to moderate the calculated weight $(\mathrm{Wj})$ of entropy method,

$$
w_{j}^{\prime}=\frac{\lambda_{j} \cdot w_{j}}{\sum_{j=1}^{n} \lambda_{j} \cdot w_{j}} \quad, \quad \forall j
$$

Because of entropy technique concept, the coefficient for attributes which have more distribution in their frequencies will be better. On the contrary, the attributes which have low distribution in their frequencies, will have lower importance. High dispersion in the 
frequencies for each attribute indicates that desired sites (alternatives) don't have same quality and quantity, but low dispersion in the frequencies can show the following two states:

i) Further alternatives have the same appropriate quality and quantity in terms of access to an attribute and providing desirability (site selection) for that attribute.

ii) More alternatives have same situation in comparison with negative point of desired attribute, on the other hand, access to quality and quantity of desired indicator is not possible (due to location and position features).

\subsubsection{Experts Opinion in Weighting of Attributes}

One of the special features of entropy approach is considering experts view points and decision makers beside the influence of facts on decision making. So that, these two aspects are combined and cause to make scientific and logical decision in determination and evaluation of site selection projects. Pairwise comparisons table is one of the most applied method to considering expert's viewpoints in determination of importance coefficients. In this way, all indicators are compared with each other and then using geometric average and normalizing, the mentioned weights are obtained.

Table 2. Type of pair wise comparison

\begin{tabular}{|c|l|l|}
\hline Score & Definition & Description \\
\hline 1 & Equal importance & Two attributes have equal importance \\
\hline 3 & $\begin{array}{l}\text { Slightly more } \\
\text { importance }\end{array}$ & $\begin{array}{l}\text { Important of an attribute is slightly more important } \\
\text { another }\end{array}$ \\
\hline 5 & More importance & Importance of an attribute is more important another \\
\hline 7 & $\begin{array}{l}\text { Much more } \\
\text { importance }\end{array}$ & $\begin{array}{l}\text { Importance of an attribute is much more important } \\
\text { another }\end{array}$ \\
\hline 9 & Absolute importance & Absolute importance of an attribute is fixed \\
\hline $2,4,6,8$ & Intermediate values & - \\
\hline
\end{tabular}

It should be considered that if the attribute importance of $A$ to $B$ is $n$, attribute importance of $B$ into A will be $1 / \mathrm{n}$.

\section{Case Study: Evaluation of New Town Site Selection in TMR}

\subsection{New Towns in Tehran Metropolitan Region (TMR): A background}

Tehran as a capital of Iran and the core metropolitan of region with about 8 million is one of the largest metropolitan areas of the world, ranking the second place in the Middle East after Cairo. The great enlargement of this city started after Second World War, when the nationalization of oil industry (1951) and the coup (1953), caused the rapidly growth of Tehran because of the involvement of Iran in the world economy. The land reforms of 1962 caused to the immigration of villages to the city and population explosion of Tehran, so that Tehran's population rose from 1.5 million in 1956 to 3 million in 1966 and 4.5 million in 1976 (Karimian, 1976). The revolution of 1979 completed the irregular and ugly physical expending of Tehran, because new government couldn't control the explosion of informal settlements and unofficial suburbs 


\section{Macrothink}

Environmental Management and Sustainable Development

ISSN 2164-7682

2014, Vol. 3, No. 1

around the city. During this period, a huge allocation of land was made to people in the lower income class. A large number of lower incomes and so some middle class citizens seized the opportunity to occupy many vacant land plots in and around Tehran. With becoming more acute of Tehran's urban problems and in order to solve the over urbanization and population, the policy of creating new towns was assigned to the Ministry of Housing and Urban Development (MHUD) and consequently the studies for locating and construction of new towns around the large cities began (Atash, 2002). Thus, the Ministry of Housing and Urban Development tried to locate new towns site in areas near major urban centres, large industrial establishments and in areas where land is owned by the government(Ziari, 2009).

Nevertheless, construction idea of new town around Tehran Metropolitan Region (TMR) has not been predicted in the initial master plan of Tehran (1968). Only based on the studies carried by ATEC Consulting Engineer Company (1985), the new towns including Hashtgerd, Pardis, Parand and Andisheh were proposed in the vicinity of Tehran (ATEC, 1985).

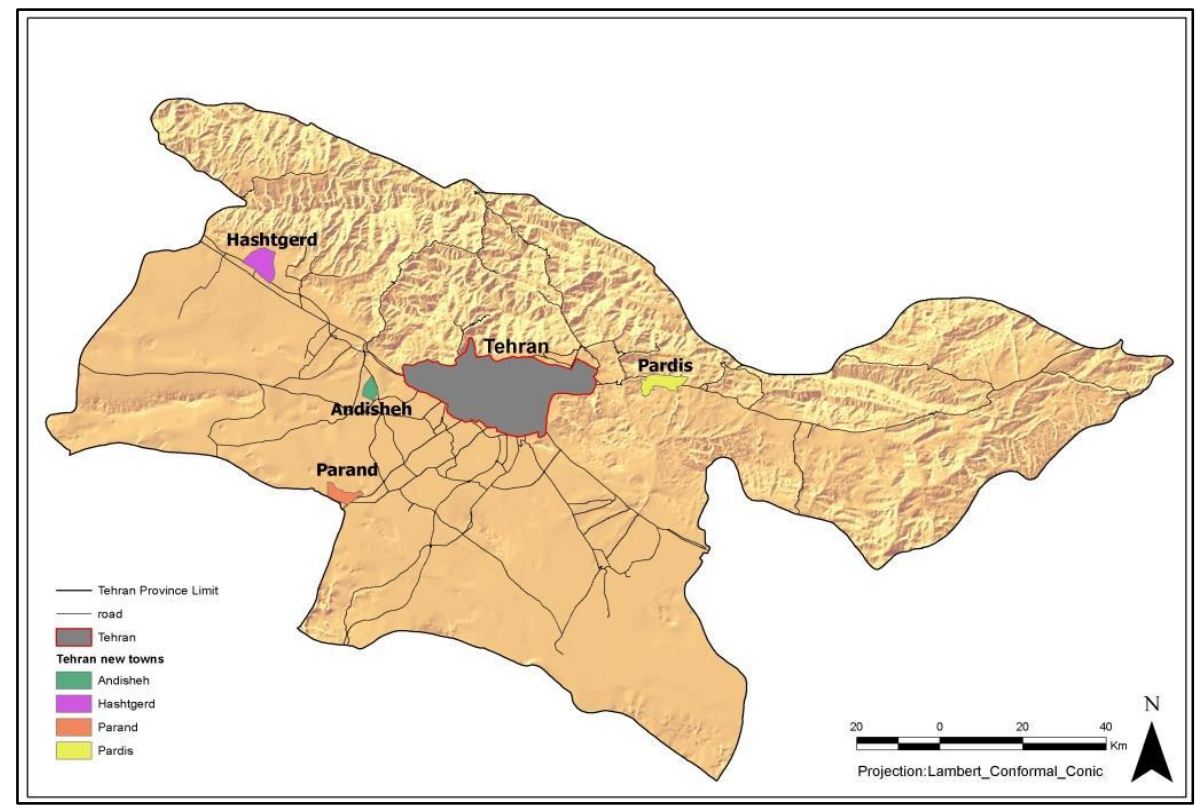

Figure 2. Location of New Towns in relation to Tehran City

However, although the new towns policy in Iran (in new functional and structural form) has been affected by the model of new British towns, they have not been successful in achieving the defined targets. For instance, the new British towns were successful in accomplishing the objectives set for working conditions, inhibition of the expansion of large cities and reducing urbanization problems (Denington, 1972). In contrary, after three decades from the new towns strategy in Iran, there are many critical perspectives in relation their structural and functional aspects. Despite this, there are a few coherent literatures that attempt to have a comprehensive assessment of this policy in Iran. This article only deals with one aspect of the complexity of new towns and it is their site selection matter.

\subsection{Effective Criterion for Evaluating the Site Selection of New Towns}

Location and position features are the first steps in site selection of new towns. So location and position indicators are important criteria for assessing process of these cities. Similarly, 


\section{Macrothink}

Environmental Management and Sustainable Development

ISSN 2164-7682

economic and infra structural features should also be considered in each site selection evaluation. These criteria are classified into main categories; the first category is named static criteria and is little changed over times. Physical and natural criteria such as topography, soil type, land capability and climate conditions are classified in this category. On contrary, dynamic criteria such as transport networks, infrastructures and economic situations are more changed over the time (Golany, 1978). Therefore, in conformity with considered goals of this paper and considering characteristics such as: Criteria of national physical plan, regulation of new towns development organization, reviewing of similar experiences and case studies and special situation of Tehran metropolitan region (TMR), the following indicators have been chosen.

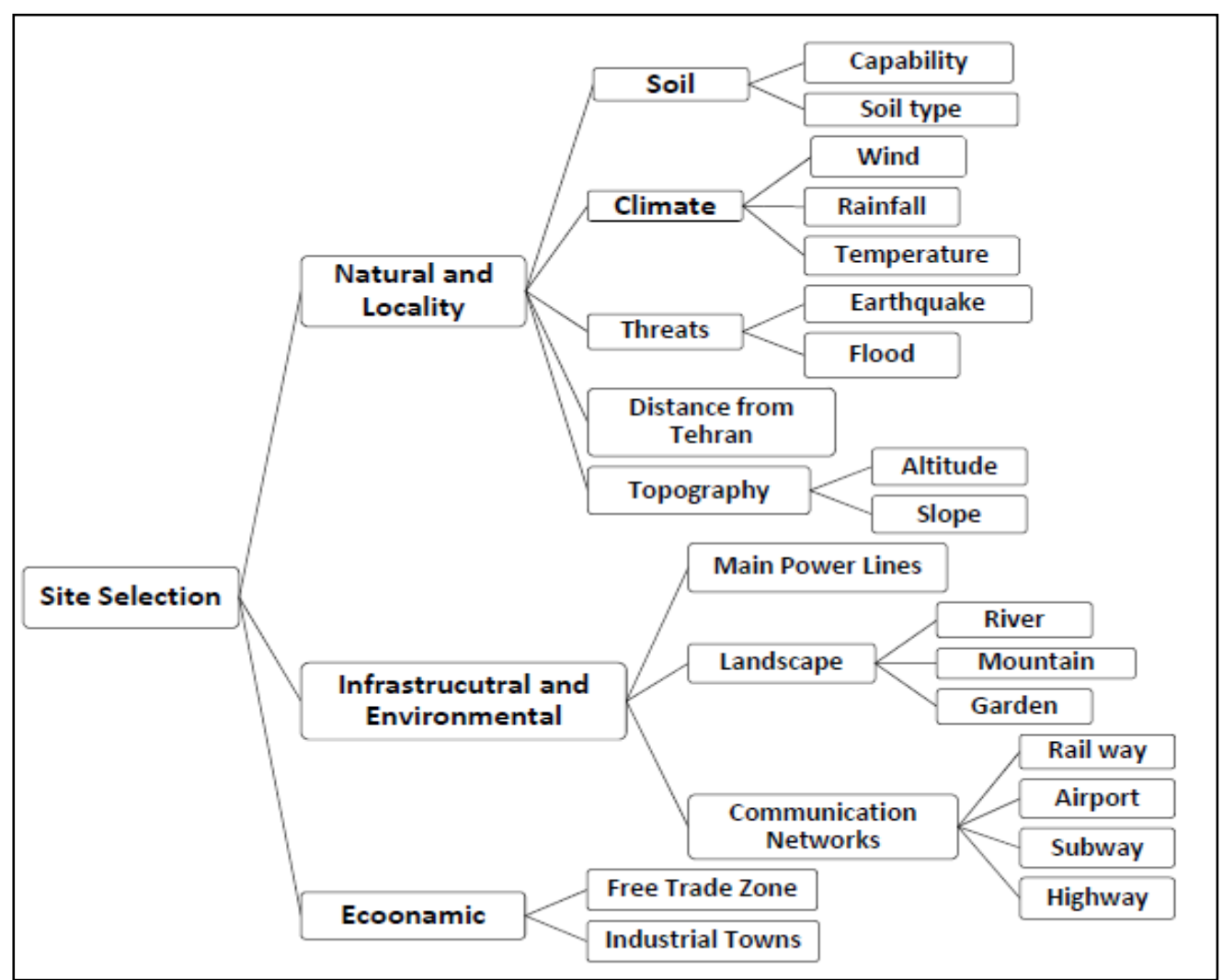

Figure 3. Selected criteria for evaluation of new town's site selection

\subsection{Determining Final Score of Alternatives (in Relation to Optimal Site Selection)}

\subsubsection{Calculation of Attributes Weight (Importance Coefficients) by Entropy}

Application of entropy will lead to determination of coefficient importance $(\mathrm{Wj})$ for each attribute. Due to the long process of calculating each indicator, here is only shown the weight of earth quake hazard attribute before applying the expert's opinions: 
Table 3. The weight of earthquake indicator using entropy

\begin{tabular}{|c|c|c|c|c|}
\hline New towns & Earth quake & Pij & LN pij & Pij. Ln pij \\
\hline Andishe & 6 & 0.333333 & -1.09861 & -0.366204096 \\
\hline Parand & 5 & 0.277778 & -1.28093 & -0.355814957 \\
\hline Pardis & 3 & 0.166667 & -1.79176 & -0.298626578 \\
\hline Hashtgerd & 4 & 0.222222 & -1.50408 & -0.334239422 \\
\hline & & & $\sum \mathrm{LN} \mathrm{pij} \mathrm{*} \mathrm{Pij}$ & -1.354885053 \\
\hline & & & $\mathrm{Ej}$ & 0.977343623 \\
\hline & & & $\mathrm{Dj}$ & 0.022656377 \\
\hline
\end{tabular}

Using the experts' opinions whose have valuable experiences in this area, is another positive points of this method. Here, final weight of attributes is calculated, these weights are computed by combination of the obtained weights from entropy and pair wise matrix methods.

Table 4. The final weight of selected attributes

\begin{tabular}{|c|c|c|c|c|c|c|}
\hline Indicators & Dj & wj & $\lambda j$ & $w j * \lambda j$ & w'j & $\begin{array}{l}\text { Final Modified } \\
\text { weights }\end{array}$ \\
\hline Earth quake & 0.022656 & 0.054912 & 6.256 & 0.3435298 & 0.2905196 & 0.290 \\
\hline Flood risk & 0.00736 & 0.017839 & 5.155 & 0.0919583 & 0.0777682 & 0.077 \\
\hline Slope & 0.00736 & 0.017839 & 3.83 & 0.0683221 & 0.0577793 & 0.057 \\
\hline Altitude & 0.0092975 & 0.022535 & 1.037 & 0.0233684 & 0.0197624 & 0.019 \\
\hline Soil type & 0.0016874 & 0.00409 & 3.01 & 0.0123103 & 0.0104107 & 0.010 \\
\hline Land capability & 0.0073605 & 0.01784 & 2.569 & 0.0458306 & 0.0387585 & 0.038 \\
\hline Wind flaw & 0.0050321 & 0.012196 & 0.244 & 0.0029759 & 0.0025167 & 0.002 \\
\hline Access to highway & 0.001258 & 0.003049 & 1.994 & 0.0060798 & 0.0051416 & 0.005 \\
\hline Access to subway & 0.0598789 & 0.14513 & 1.676 & 0.2432385 & 0.2057043 & 0.205 \\
\hline Distance from industrial town & 0.0212964 & 0.051617 & 1.464 & 0.0755669 & 0.0639062 & 0.063 \\
\hline Main power lines & 0.0000006 & 1.457636 & 1.32 & 1.924906 & 1.623606 & 1.623 \\
\hline Distance from airport & 0.047562 & 0.115278 & 0.504 & 0.0580999 & 0.0491344 & 0.049 \\
\hline Distance from railway station & 0.039105 & 0.09478 & 0.426 & 0.0403763 & 0.0341458 & 0.034 \\
\hline Landscape (gardens) & 0.010655 & 0.025825 & 0.335 & 0.0086513 & 0.0073163 & 0.007 \\
\hline Landscape (mountain) & 0.010758 & 0.026075 & 0.279 & 0.0072748 & 0.0061522 & 0.006 \\
\hline Landscape (river) & 0.020563 & 0.049839 & 0.299 & 0.0149019 & 0.0126024 & 0.012 \\
\hline Temperature & 0.015487 & 0.037536 & 0.91 & 0.0341581 & 0.0288871 & 0.028 \\
\hline Rainfall & 0.010757 & 0.026072 & 0.798 & 0.0208055 & 0.017595 & 0.017 \\
\hline Distance from free trade zone & 0.083868 & 0.203273 & 0.199 & 0.0404514 & 0.0342093 & 0.034 \\
\hline Distance from Tehran & 0.030645 & 0.074275 & 0.6 & 0.0445651 & 0.0376883 & 0.037 \\
\hline
\end{tabular}

0.4125874

1.182467 


\section{Macrothink}

Environmental Management and Sustainable Development

ISSN 2164-7682

2014, Vol. 3, No. 1

\subsubsection{Calculate the Separation Measure (from Positive and Negative Solutions)}

As mentioned before, relative distance of options to the positive and negative ideal solution provides the possibility of real evaluation and analysis of alternatives. On the other hand, the existence of negative and positive solutions shows the existent situation of each alternative.

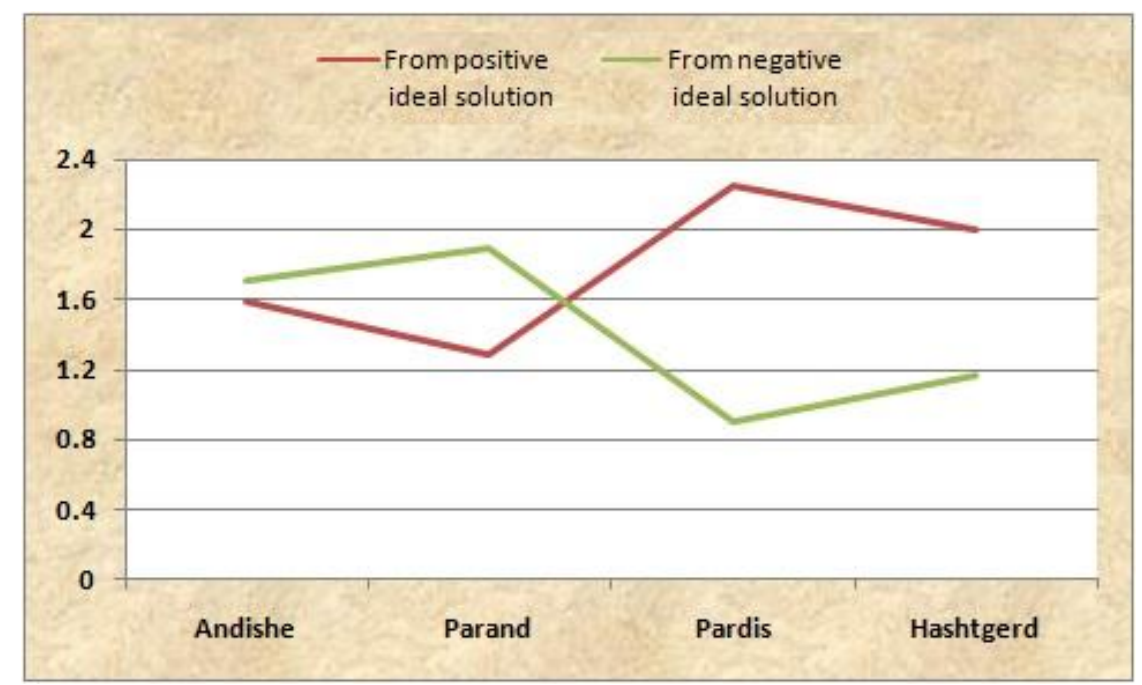

Figure 4. Distance from positive and negative ideal solutions

As can be seen, New Town of Pardis has the most distance from positive solution (site selection) and the least distance from negative ideal solution. On contrary, New Town of Parand has the least interval from positive solution and the most from negative solution. It means that Parand City is in the most distance from negative solution and Pardis is in the least distance.

\subsubsection{Final Rating and Ranking of Alternatives}

In terms of closeness to the positive ideal solution, New Town of Parand has more favourable situation and is the closer option to the optimal site selection. New Towns of Pardis has the most distance from the positive ideal solution and the shortest distance from the negative ideal solution.

Table 5. Rating of alternatives in terms of relative closeness to ideal solution

\begin{tabular}{|c|c|c|c|c|}
\hline new towns & $\begin{array}{l}\text { Distance from } \\
\text { negative ideal } \\
\text { solution }\end{array}$ & $\begin{array}{l}\text { Distance from } \\
\text { positive ideal } \\
\text { solution }\end{array}$ & & $\begin{array}{c}\text { Relative } \\
\text { closeness to } \\
\text { ideal solution }\end{array}$ \\
\hline & Di - & $\mathrm{Di}+$ & $(\mathrm{Di}-+\mathrm{Di}+)$ & Cli \\
\hline Andishe & 1.7091 & 1.5855 & 3.2946 & 0.518758 \\
\hline Parand & 1.8963 & 1.2883 & 3.1846 & 0.595459 \\
\hline Pardis & 0.9055 & 2.2473 & 3.1528 & 0.287205 \\
\hline Hashtgerd & 1.1646 & 2.0014 & 3.166 & 0.367846 \\
\hline
\end{tabular}




\section{$\Lambda$ Macrothink}

\subsubsection{Results}

The results of site selection assessment using TOPSIS approach are summarized in Figure 7. Based on the relative closeness to ideal site selection, the ranking of the existence alternatives descending order are Parand, Andishe, Hashtgerd and Pardis New Towns. According to the results, New Town of Parand has the optimal site location. On the other hand, if the site selection studies were performed before the starting of construction, the other alternatives could have been eliminated. Because based on TOPSIS concept, the selected alternative should have the most distance from positive solution (site selection) and the minimum distance from negative solution. Recently, Ministry of Housing and Iran's Parliament have approved this city as the optimal city for transhipment of administrative capital of Iran from Tehran City. This city has also the largest population increase in Tehran province after Tehran. These factors indicate that considered criteria and method for assessing can be applied in similar urban and regional projects.

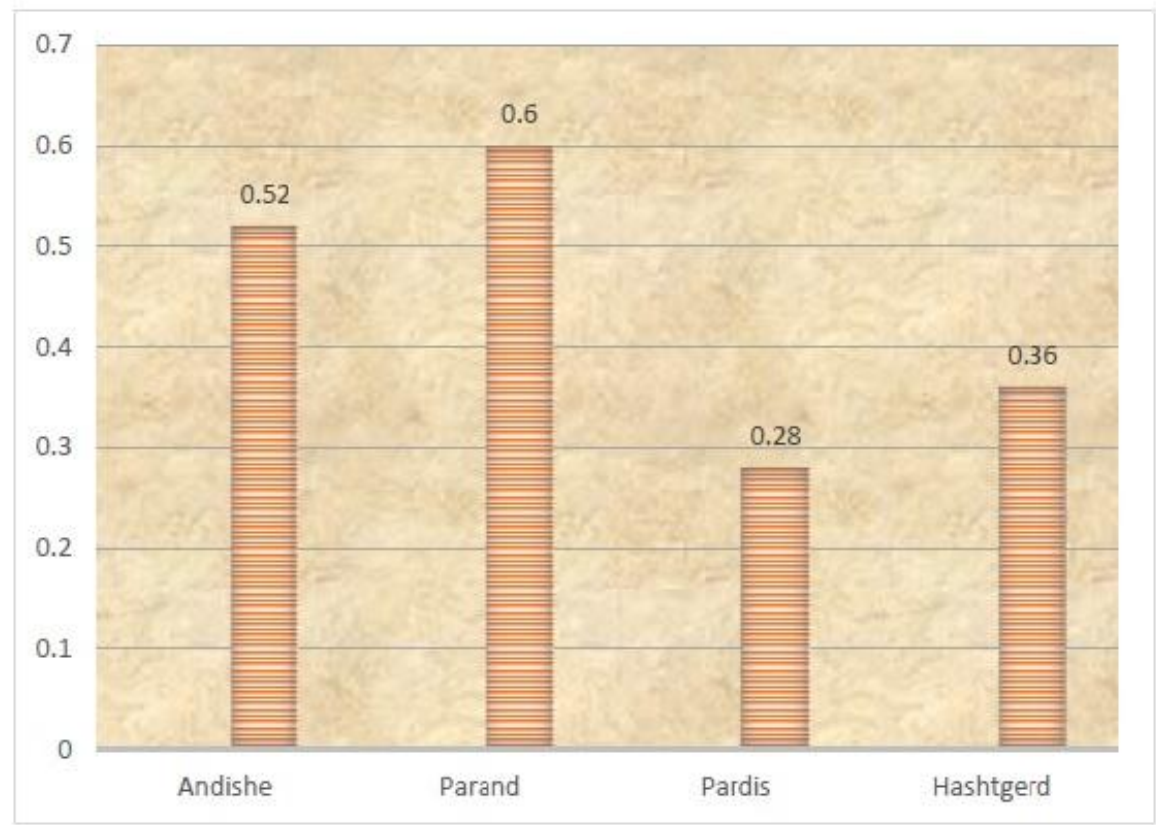

Figure 5. Final ranking of studied New Towns in aspect of site selection

\section{Conclusion}

Site selection projects and especially site selection of new towns (due to its importance as a human settlement) need more sensitive and precise mechanisms to adapt variety data and information. Therefore, by using MCDM methods, uncertainty and vagueness from subjective perception and the experiences of decision - maker can be effectively represented and reached to a more effective decision. In this study, we have re-evaluated the site selection of New Towns in Tehran Metropolitan Region (TMR) using TOPSIS method. In location planning of new towns the attributes have increasing or decreasing influence to each other. For example, appropriate access to main communication network can compensate the high distance from industrial towns or economic activity centres. Therefore, we need to use the compensatory methods (such as TOPSIS). Whereas, the attributes of each level in methods such as AHP should basically be independent to each other (without any increasing or decreasing influence). 


\section{Macrothink}

Environmental Management and Sustainable Development

ISSN 2164-7682

2014, Vol. 3, No. 1

Besides, the prior existence of decision making matrix proves that using the pair wise matrix for determination of weights (such as AHP) is not enough. Hence, the effect of each attribute is firstly evaluated by entropy and then by using pair wise comparison matrix, the adjusted weights are obtained (Simultaneous consideration of facts and ideals). However, this paper has tried to represent the capability of MCDM methods in urban and regional planning issues and application necessity of methodological approaches in multi - dimensional decision making process, where decisions have multi-dimensional consequences on quality of urban spaces.

\section{References}

Asgharpour, M. (2004). Multi Criteria Decision Making (MCDM). Tehran: University of Tehran. Iran.

Awasthi, A. C. (2011). A multi-criteria decision making approach for location planning for urban distribution centers under uncertainty. Mathematical and Computer Modelling, 53(1-2), 98-109.

Banietema, G. (1992). Studying of New Towns of world. The proceeding of New Towns Conference. Tehran: Publication of Ministry of Housing.

C. Kahraman, D. R. (2003). Fuzzy group decision-making for facility location selection. Information Sciences, 157, 135-153.

Chen, C. (2001). A fuzzy approach to select the location of the distribution center. Fuzzy Sets and Systems $118,65-73$.

Chou, J.-F. D.-C. (2013). An Evaluation Model of Quantitative and Qualitative Fuzzy Multi-Criteria Decision-Making Approach for Location Selection of Transshipment Ports. Hindawi Publishing.

Chu, T. (2002). Facility location selection using fuzzy TOPSIS under group decisions, International Journal of Uncertainty. Fuzziness and Knowledge-Based Systems, 10(6), 687701.

Denington, E. (1972). New Towns for Whoms: The British Experience. Charles knight and Co. Ltd, .

Engineering, A. C. (1985). Urban Region Plan of Tehran. Tehran: ATEC Press.

Golany, G. (1978). New town Planning: Principles and Practice. John Wiley \& Sons.

Karimian, H. (1976). ehran in Past and Present Time. Tehran. Iran.

Keeney, R. R. (1976). Decisions with Multiple Objectives. Cambridge: Cambridge University Press.

Lixing Yang, X. J. (2007). Logistics distribution centers location problem and algorithm under fuzzy environment. Journal of Computational and Applied Mathematics, 208(2), 303-315.

Mandelker, D. R. (1965). Some Policy Considerations in the Drafting of New Towns 


\section{Macrothink \\ Environmental Management and Sustainable Development \\ ISSN 2164-7682 \\ 2014, Vol. 3, No. 1}

Legislation. Washington University Law Review, Issue 1, New Towns Development.

Markovic, Z. (2010). Modification of TOPSIS Method for Solving of Multi Criteria Tasks. Journal of Operation Research, 20, 117-143.

Onüt. S, S. S. (2008). Transshipment site selection using the AHP and TOPSIS approaches under fuzzy environment. Waste management, 28(9), 1552-9. .

S.Y. Chou, Y. C. (2008). A fuzzy simple additive weighting system under group decision making for facility location selection with objective/subjective attributes. European Journal of Operational Research, 189(1), 132-145.

Siddiqui, M. E. (1996). Landfill siting using geographic informatin a demonstration. Journal of Envi- ronmental Engineering, 122, 515-523.

Sumathi, V. R. (2008). GIS-based approach for optimized siting of municipal solid waste landfill. Wast Management, 28, 2146-2160.

Sumathi, V. R. (2008). GIS-based approach for optimized siting of municipal solid waste landfill. Waste management, 28(11), 2146-60.

Yang. T, H. C. (2007). Multiple-Attribute Decision Making Methods for Plant Layout Design Problem. Elsevier, Integrated Manufacturing, 23, 126 - 137.

Yoon, K. H.-L. (1995). Multi Attribute Decision Making: An Introduction. In: Thousand Oaks. Sage Publications, Inc.

Zebardast, E. (2001). Application of Analytical Hierarchy Process (AHP) in Urban and Regional Planning. Fine arts, 49, 79-90.

Zeleny, M. (1982). Multiple Criteria Decision Making. New York: McGraw-Hill, Inc.

Ziari, K. (2009). A Study of Iranian New Towns During Pre and Post Revolution. Int. J. Environ. Res, 3(1), 143-154.

\section{Copyright Disclaimer}

Copyright reserved by the author(s).

This article is an open-access article distributed under the terms and conditions of the Creative Commons Attribution license (http://creativecommons.org/licenses/by/3.0/). 